\title{
Flexural strength of nano-hybrid resin composite as a function of light attenuation distance and specimen dimension
}

\author{
El-Askary, Farid Sabry ; Botros, Sara Adel ; Nassif, Mohamed Salah Abdelaziz ; Özcan, Mutlu
}

\begin{abstract}
This study evaluated ascending order of light attenuation distance $(0,2,4,8 \mathrm{~mm})$ and specimen dimensions $(2 \times 2 \times 10,2 \times 2 \times 12,2 \times 2 \times 15 \mathrm{~mm} 3)$ differing from requirements of ISO $4049(2 \times 2 \times 25 \mathrm{~mm} 3)$ on the flexural strength of nano-hybrid resin composite. Specimens $(\mathrm{N}=160)$ were prepared accordingly and randomly assigned into groups for the factors studied. Specimens were photo-polymerized from increased distances through 1,2 , 3 and 5 overlapping cycles depending on the specimen length after which they were subjected to three-point bending test $(0.5 \mathrm{~mm} / \mathrm{min})$. Data were statistically analyzed using one-way, two-way ANOVA and Tukey's HSD post-hoc tests $(\alpha=0.05)$. Two-parameter Weibull modulus, scale $(\mathrm{m})$ and shape $(0)$ were calculated. Both light attenuation distance $\left(\mathrm{p}^{<0.001)}\right.$ and specimen dimensions $\left(\mathrm{p}^{<0.001)}\right.$ significantly affected the results. Regardless of the specimen dimensions, $0,2 \mathrm{~mm}$ polymerization distance resulted in significantly higher mean flexural strength compared to 4 and $8 \mathrm{~mm}$. Polymerization distance did not significantly affect the mean flexural strength of specimens prepared according to ISO norms $(\mathrm{p}>0.05)$. Weibull distribution presented the highest shape $(\mathrm{m})$ for $10-8$ $\mathrm{mm}$ (24.65), 12-4 mm (14.54), 15-2 mm (12.32), 25-2 mm (17.56), length-light distance combinations. Specimen dimensions prepared in accordance with ISO 4049 do not allow for comparison of the effect of light attenuation distance on the flexural strength of resin composite tested.
\end{abstract}

DOI: https://doi.org/10.1080/01694243.2016.1221251

Posted at the Zurich Open Repository and Archive, University of Zurich ZORA URL: https://doi.org/10.5167/uzh-146588

Journal Article

Accepted Version

Originally published at:

El-Askary, Farid Sabry; Botros, Sara Adel; Nassif, Mohamed Salah Abdelaziz; Özcan, Mutlu (2017). Flexural strength of nano-hybrid resin composite as a function of light attenuation distance and specimen dimension. Journal of Adhesion Science and Technology, 31(5):520-529.

DOI: https://doi.org/10.1080/01694243.2016.1221251 


\section{Flexural Strength of Nano-hybrid Resin Composite as a Function of Light Attenuation Distance and Specimen Dimension}

Farid Sabry El-Askarya, Sara Adel Botros ${ }^{b}$, Mohamed Salah Abdelaziz Nassif ${ }^{c}$, Mutlu Özcan ${ }^{d}$

a Professor, Operative Dentistry Department, Faculty of Dentistry, Ain Shams University, African Unity Organization Street, Abbassia 11566, Cairo, Egypt. Tel: 002-01002500177. Email address: faridelaskary@asfd.asu.edu.eg

b Teaching Assistance, Operative Dentistry Department, Faculty of Dentistry, British University in Egypt, El Sherouk City , Suez Desert Road , Cairo 11837. Tel: 00201000381136. E-mail address: saraadel88@hotmail.com

c Assistant Professor, Dental Biomaterial Department, Faculty of Dentistry, Ain Shams University, African Unity Organization Street, Abbassia 11566, Cairo, Egypt. Tel: 00201001520980. E-mail address: Mohamed.salah.abdelaziz@asfd.asu.edu.eg

d Professor, University of Zurich, Dental Materials Unit, Center for Dental and Oral Medicine, Clinic for Fixed and Removable Prosthodontics and Dental Materials Science, Plattenstrasse 11, CH-8032, Zürich, Switzerland. Tel.: +41-44-6345600; Email address: mutluozcan@hotmail.com

Short Title: Flexural strength of nano-hybrid resin composite. 
Corresponding author:

Prof. Dr. Farid Sabry El-Askary, Operative Dentistry Department, Faculty of Dentistry, Ain Shams University, African Unity Organization Street, Abbassia 11566, Cairo, Egypt. Tel: 002-01002500177. Fax: 002-22601218. E-mail address: faridelaskary@asfd.asu.edu.eg. 


\section{Abstract}

This study evaluated ascending order of light attenuation distance $(0,2,4,8 \mathrm{~mm})$ and specimen dimensions $\left(2 \times 2 \times 10,2 \times 2 \times 12,2 \times 2 \times 15 \mathrm{~mm}^{3}\right)$ differing from requirements of ISO $4049\left(2 \times 2 \times 25 \mathrm{~mm}^{3}\right)$ on the flexural strength of nano-hybrid resin composite. Specimens ( $\mathrm{N}=160)$ were prepared accordingly and randomly assigned into groups for the factors studied. Specimens were photo-polymerized from increased distances through 1, 2, 3 and 5 overlapping cycles depending on the specimen length after which they were subjected to three-point bending test $(0.5 \mathrm{~mm} / \mathrm{min})$. Data were statistically analyzed using one-way, twoway ANOVA and Tukey`s HSD post-hoc tests $(\alpha=0.05)$. Two-parameter Weibull modulus, scale $(m)$ and shape $(0)$ were calculated. Both light attenuation distance $(\underline{p}<0.001)$ and specimen dimensions $(\underline{p<0.001})$ significantly affected the results. Regardless of the specimen dimensions, $0,2 \mathrm{~mm}$ polymerization distance resulted in significantly higher mean flexural strength compared to 4 and $8 \mathrm{~mm}$. Polymerization distance did not significantly affect the mean flexural strength of specimens prepared according to ISO norms $(p>0.05)$. Weibull distribution presented the highest shape $(m)$ for $10-8 \mathrm{~mm}$ (24.65), 12-4 mm (14.54), 15-2 mm (12.32), 25-2 mm (17.56), length-light distance combinations. Specimen dimensions prepared in accordance with ISO 4049 do not allow for comparison of the effect of light attenuation distance on the flexural strength of resin composite tested.

Key Words: flexural strength, ISO 4049, photo-polymerization, resin composite. 


\section{Introduction}

Over the past decades, dental profession endorsed substantial evolution in the field of resin composite materials providing clinicians with an increased array of minimal invasive therapy options in restoring teeth. Since dental restorations are routinely subjected to complex intraoral forces during natural masticatory function with a considerable amount of flexural stresses, [1] resin composite restorations are also expected to have mechanical properties to meet the clinical requirements for restorations of both anterior and posterior teeth. In this regard, appropriate polymerization of resin composites is essential. Low degrees of conversion could reduce physical and mechanical properties, increase solubility, microleakage, pulp irritation and discoloration compromising the long-term service of such materials. [2-10] The polymerization reaction of resin composite materials mainly depends on the absorption of adequate amount of light energy in order to activate the photo-initiator molecules, start their collision with the amines and forming free radicals that initiate the polymerization. [11] Yet, in some clinical situations, resin composite materials might not be ideally accessible to the tip of the photo-polymerization unit. This could be encountered in cavities with deep proximal boxes where the gingival floor could be more than $8 \mathrm{~mm}$ away from the light source, [12] especially with buccal and lingual wall convergence towards the occlusal surface. In such a case, light intensity reaching the first increment of the material surface, which is typically on the gingival floor, could be strongly attenuated, leading to decreased degree of conversion of the resin material, thereby impeding adequate polymerization. $[13,14]$

International Standards Organization (ISO) norm 4049, [15-16] advocates the flexural strength as an important property for screening mechanical properties of resin-based materials and predicting their clinical performance upon loading. [17] It is defined as the 
maximum stress that a material can resist before failure when subjected to bending load. [18] Hence, high flexural properties are desirable where heavy masticatory stresses are encountered during clinical service. [19] In accordance with ISO 4049 (2000), [16] threepoint flexural strength test necessitates the use of rectangular bar specimens (thickness: 2 $\mathrm{mm}$, height: $2 \mathrm{~mm}$, length: $25 \mathrm{~mm}$ ) onto which tensile stresses are exposed. Apart from waste of material, large bar-shaped specimens according to the requirements of ISO 4049 (2000), are challenging to prepare without entrapment of flaws. [1, 20, 21] Furthermore, the dimensions required for ISO 4049 are not representative of the clinical restoration options. [22] Since the length of the specimen according to the norm exceed the exit window diameter of photo-polymerization device tips, that range on average between 7 and $12 \mathrm{~mm}$, several overlapping irradiation sequences are required that consequently leads to nonuniform polymerization of resin composite specimens [23-26] and unreliable flexural strength data. [21, 26] Accordingly, smaller size specimen dimensions might be representative for clinical restorative scenarios. [8, 25, 27, 28] Yet, advances in new polymers and polymerization devices require information on possible effect of specimen dimensions on mechanical properties of resins that also relates to other parameters associated with polymerization characteristics.

The objectives of this study therefore were to investigate the effect of ascending order of light attenuation distance on the flexural strength of nano-hybrid resin composite specimens prepared with dimensions in accordance with and differing from the ISO 4049 norm (2000). The null hypothesis tested was that neither light attenuation distance nor the specimen dimensions would affect the flexure strength of the tested material. 


\section{Materials and Methods}

\subsection{Specimen Preparation}

Specimens $(\mathrm{N}=160, \mathrm{n}=10$ per group) were prepared using a nano-hybrid resin composite (Grandio, Shade A2, VOCO GmbH, Couxhaven, Germany) based on bis-phenol A-Glycedyl methacrylate (bis-GMA), Urethane dimethacrylate (UDMA), Triethylene glycol dimethacrylate (TEGDMA), glass ceramic and $\mathrm{SiO}_{2}$ fillers. The specimens were divided into 16 groups according to the two experimental factors investigated, namely light attenuation distance $(0 \mathrm{~mm}, 2 \mathrm{~mm}, 4 \mathrm{~mm}$ and $8 \mathrm{~mm})$ from specimen surface and specimen dimensions $(2 \mathrm{~mm} \times 2 \mathrm{~mm} \times 10 \mathrm{~mm}, 2 \mathrm{~mm} \times 2 \mathrm{~mm} \times 12 \mathrm{~mm}, 2 \mathrm{~mm} \times 2 \mathrm{~mm} \times 15 \mathrm{~mm}$ and $2 \mathrm{~mm} \times 2 \mathrm{~mm} \times 25$ $\mathrm{mm})$.

\subsection{Preparation of resin composite models}

Initially, resin composite model was prepared in a stainless steel split-mould with central rectangular cavity. The stainless steel mould $(2 \mathrm{~mm} \times 2 \mathrm{~mm} \times 25 \mathrm{~mm})$ was fixed on a polytetrafluoroethylene (PTFE) base covered by a polyester strip (Stripmat, Polydentia, Mezzovico, Switzerland). The resin composite was applied into the mould, covered by another polyester strip and gently pressed using a glass slide. The glass slide was then removed and the resin composite material was photo-polymerizad with 5 overlapping photopolymerization cycles using an LED unit (Elipar, 3 M ESPE, St. Pail, USA; tip diameter: 10 $\mathrm{mm}$; light intensity: $1200 \mathrm{~mW} / \mathrm{cm}^{2}$ ). Thereafter, resin composite model was removed from the mould, flashes were eliminated manually using \#600 SiC paper (\#600, Cumi SiC Paper, Moxie Supply, Noida, India), specimen dimensions were verified using a digital caliper (Absolute AOS Digimatic, Mitutoyo, Tokyo, Japan). For the other dimensions, the over mentioned steps were repeated and the resulted resin composite bars $(2 \mathrm{~mm} \times 2 \mathrm{~mm} \times$ $25 \mathrm{~mm}$ ) were reduced to the other respective dimensions $(2 \mathrm{~mm} \times 2 \mathrm{~mm} \times 10 \mathrm{~mm}, 2 \mathrm{~mm} \times$ $2 \mathrm{~mm} \times 12 \mathrm{~mm}$ and $2 \mathrm{~mm} \times 2 \mathrm{~mm} \times 15 \mathrm{~mm}$ ) by careful cutting the excess length using low 
speed diamond coated discs with copious water irrigation. The length of each model was verified using the digital caliper.

Each resin composite model was fixed on a glass slide using cyanoacrylate adhesive. A rectangular metallic mould with internal cavity (height: $6 \mathrm{~mm}$, width: $8 \mathrm{~mm}$, length: $30 \mathrm{~mm}$ ) was used as an impression tray. The metallic piece was fixed over the glass slide and an equal amount of the base and the catalyst of the putty mix addition silicone impression material was mixed according to manufacturer's instruction. The mix was packed inside the mould and pressed using another glass slide until setting. The metallic piece was removed with the impression material (Zhermach Impression System, Zharmach SpA, Badia Polesine, Italy), light body was injected around the model and the putty mix was reinserted over the light body and gently pressed until complete setting. The impression was removed and the excess material was trimmed using surgical blade \#11.

\subsection{Preparation of resin composite bars}

Resin composite material was packed inside the respective silicon mould, covered with a polyester strip and gently pressed using a glass slide to extrude excess material. The glass slide was then removed and for the $2 \mathrm{~mm} \times 2 \mathrm{~mm} \times 10 \mathrm{~mm}$ specimens, resin composite was photo-polymerized using single photo-polymerization cycle for $20 \mathrm{~s}$ according to manufacturer's instructions. For the $2 \mathrm{~mm} \times 2 \mathrm{~mm} \times 12 \mathrm{~mm}$ specimens, resin composite was photo-polymerized with two overlapping cycles from each end of the specimen, of 20 s each. Specimens with $2 \mathrm{~mm} \times 2 \mathrm{~mm} \times 15 \mathrm{~mm}$ dimensions, three photo-polymerization cycles of $20 \mathrm{~s}$ each were used. The first cycle started at the middle of the specimen and the other two cycles overlapped the first cycle at the two ends of the specimen in order to cover the whole length of the specimen. For the $2 \mathrm{~mm} \times 2 \mathrm{~mm} \times 25 \mathrm{~mm}$ specimens, five polymerization cycles

of 20 s each were practiced. The first polymerization cycle started at the middle of the specimen and the other four cycles overlapped the first cycle at the two ends of the 
specimen to cover the whole length of the specimen (Figs 1a-d). In order to standardize the distance between the tip of the light source and the specimen, three metallic spacers with $2 \mathrm{~mm}, 4 \mathrm{~mm}$ and $8 \mathrm{~mm}$ thicknesses, having central holes of $8 \mathrm{~mm}$ width and $25 \mathrm{~mm}$ length were used to control the photo-polymerization of $2 \mathrm{~mm}, 4 \mathrm{~mm}$ and $8 \mathrm{~mm}$ distances. For the Omm distance, specimens were photo-polymerized directly over the polyester strip (Figs. 2a-d). Specimens were then wet finished from their length using silicon carbide paper (\#1000) to remove the resin composite flashes. The specimens were stored in distilled water at $37^{\circ} \mathrm{C}$ for $24 \mathrm{~h}$ prior to flexural strength test.

\subsection{Flexural Strength Test}

Specimens were subjected to three-point flexural strength test in a Universal Testing Machine (Lloyd instrument LR 5K series, London, UK) at a crosshead speed of $0.5 \mathrm{~mm} / \mathrm{min}$ until fracture. Four different pairs of supporting metallic rods (diameter: $2 \mathrm{~mm}$ each) and four different distances between each two supporting rods were used established $(8 \mathrm{~mm}, 10 \mathrm{~mm}$, $13 \mathrm{~mm}$ and $20 \mathrm{~mm}$ for the $10 \mathrm{~mm}, 12 \mathrm{~mm}, 15 \mathrm{~mm}$ and $25 \mathrm{~mm}$ length specimens, respectively) (Figs. 3a-d). The load was applied at the centre of the top surface of each specimen using a third rod (2mm diameter) until failure through a loading jig ending. The maximum fracture load (Newton) for each specimen was recorded, and the flexural strength in MPa, was calculated according to the following equation:

Flexure strength $=3 F L / 2 b d^{2}$

where $F$ was the maximum fracture load in Newton, $L$ was the distance between the two supports in $\mathrm{mm}, \mathrm{b}$ and $\mathrm{d}$ were the width and the thickness of the specimens in $\mathrm{mm}$, respectively.

\subsection{Statistical Analysis}

Statistical analysis was performed using a statistical software program (SPSS 20.0; SPSS Inc., Chicago, IL, USA). Data (MPa) were analyzed using two-way ANOVA where flexural 
strength was the dependent parameter and polymerization distance (4 levels: 0,2,4,8 $\mathrm{mm}$ ) and specimen dimensions (4 levels: $2 \times 2 \times 10,2 \times 2 \times 12,2 \times 2 \times 15,2 \times 2 \times 25 \mathrm{~mm}^{3}$ ), as independent parameters. Multiple comparisons were made using Tukey`s HSD post hoc test. Maximum likelihood estimation without a correction factor was used for 2-parameter Weibull distribution, including the Weibull modulus, scale $(m)$ and shape $(0)$, to interpret predictability and reliability of adhesion (Minitab Software V.16, State College, PA, USA). $P$ values less than 0.05 were considered to be statistically significant in all tests.

\section{Results}

Both the light attenuation distance $(\underline{p<0.001})$ and specimen dimensions $(\underline{p<0.001})$ significantly affected the mean flexural strength of the resin composite (Table 1). Interactions between the two factors were not statistical $(p=0.2)$

The increase in distance from the light source $(0$ to $8 \mathrm{~mm})$ did not affect the mean flexural strength within groups with the same dimensions (one-way ANOVA, Tukey`s) (Table 2). Specimens with 10 and $12 \mathrm{~mm}$ length showed the highest mean values compared to $15 \mathrm{~mm}$ length specimens at 2 and $4 \mathrm{~mm}$ distance $(p<0.05)$.

Regardless of specimen dimensions, while light attenuation distance of 0 and $2 \mathrm{~mm}$ showed significantly higher values than those polymerized from distances of 4 and $8 \mathrm{~mm}(p<0.05)$, this parameter did not significantly affect the mean flexural strength of $25 \mathrm{~mm}$ length specimens $(p>0.05)$.

For $10 \mathrm{~mm}$ length specimens, polymerization distance of $2 \mathrm{~mm}$ presented the highest mean flexural strength value, while $8 \mathrm{~mm}$ showed significantly the lowest $(p<0.05)$. For 12 and 15 $\mathrm{mm}$ length specimens, $0 \mathrm{~mm}$ polymerization distance showed significantly higher mean values, while $4 \mathrm{~mm}$ and $8 \mathrm{~mm}$ showed the lowest. 
Weibull distribution presented the highest shape $(m)$ for $10-8 \mathrm{~mm}(24.65), 12-4 \mathrm{~mm}(14.54)$, 15-2 mm (12.32), 25-2 mm (17.56), length-light distance combinations (Table 3).

\section{Discussion}

In this study the effect of ascending order of light attenuation distance and specimen dimension on the flexural strength of nano-hybrid resin composite was investigated. Since both the light source distance and the dimensions affected the results significantly, the null hypothesis tested could be rejected.

One of the major aspects affecting the long-term clinical performance of resin composite restorations is their mechanical durability under complex stresses during chewing. [29] Reproduction of complex dynamic stresses ex vivo is both challenging and costly but static load tests, such as compressive, diametral tensile or flexural strength may help ranking material properties prior to clinical trials. [30] Among various static tests, flexural strength tests are considered profound to evaluate minor substructure changes between resin composite materials compared to compressive test. [31] The ISO 4049 (ISO 2000) [16] norm employed in this study requires rectangular prism shaped specimens (width: 2, thickness: 2, length: $25 \mathrm{~mm}$ ) that is loaded at its centre using the knife-edge attachment with support span length of $20 \mathrm{~mm}$. Unfortunately, such long span specimens could not be fabricated free of defects that might adversely affect the ultimate strength. [25] Furthermore, the diameter of the photo-polymerization device tip, often ranging from 6 to $12 \mathrm{~mm}$, could not achieve complete polymerization of the span in one attempt, similar to most clinical conditions. Thus, optimal polymerization of long-span or large surfaces requires overlapping polymerization cycles that may expose some areas longer polymerization duration than the manufacturer's suggestion. Consequently, the overlapped areas could be polymerized beyond the adjacent ones especially in long span specimens. Accordingly, in this study, 
specimens in smaller dimensions were practiced in order to overcome such drawbacks of the recommended specimen size after ISO 4049 (2000). The choice of 10, 12 and $15 \mathrm{~mm}$ specimen length, with 8,10 and $13 \mathrm{~mm}$ span length respectively, in this study was based on the biometric measurement of the human teeth. [32] In this regard, the $8 \mathrm{~mm}$ span length represented nearly the maximum mesio-distal width of premolars and canines ( 8 to 8.03 $\mathrm{mm}$, respectively). [32] Similarly, the $10 \mathrm{~mm}$ span length represented the maximum mesiodistal width, bucco-lingual and inciso-cervical dimensions for most of the human teeth and finally $13 \mathrm{~mm}$ span length, the maximum mesio-distal width and bucco-lingual dimension of the upper first molar teeth $(12.4 \mathrm{~mm})$. [32]

In this study, the dimension of the specimens showed a significant effect on the flexural strength where the shortest length $(10 \mathrm{~mm})$ demonstrated the highest flexural strength. Shorter span length between the supports during load exposure could decrease bending of the specimen, decrease the tensile strength and consequently, could lead to higher flexural strength values. Furthermore, the shear stresses could be expressed near the supports that showed no significant effect on the flexural strength of large span specimens. [25] When the span between supports is short, the flexure strength could express complex stresses as compressive, tensile and shear, [25] that might explain the higher flexural strength of the 10 $\mathrm{mm}$ specimen length. On the other hand, the smaller the dimensions of the specimen, the more sensitive the flexural strength test to the variations in the light attenuation distance from which the material was irradiated, namely increasing the distance led to decrease in the flexural strength. Specimen dimensions according to ISO 4049 (2000) [16] could not compare the effect of various light distances, which could be attributed to the higher number of overlapping polymerization cycles (5 overlaps) compared to other specimen dimensions. Thus, the repeated overlaps could mask the influence of light attenuation by increasing the distance from the light source. 
The ideal situation to adequately polymerize resin composite is to place the tip of the polymerization device directly in contact with the material [33] that is clinically not realistic. The material tested was a nano-hybrid resin composite with filler loading of $87 \mathrm{wt} \%$. As the depth of the light penetration through the material is inversely proportioning to the penetration coefficient of the material, higher filler loading might lead to more scattering and absorption of the light. [34] According to the inverse-square low (intensity is inversely proportional to the square distance), the increase in the light distance resulted in the decrease in the power density of the photo-polymerization unit. [33, 35] Increasing the distance could decrease the overall polymerization of the material, [36] and hence it might decrease the flexural strength. [37] In addition, increasing the distance up to $6 \mathrm{~mm}$ could decrease the polymerization at the bottom compared to upper portions of the resin composite implying that increasing the light distance would not allow sufficient light at the tensile part of the specimen and eventually decrease the flexure strength of the resin composite.

The use of specimen specifications according to ISO 4049 (2000) [16] could be useful in comparing mechanical properties of different resin composites but apparently, the dimensions would not allow testing the variable, effect of light attenuation distance on the mechanical properties. This could be explained on the grounds that when the specimen is loaded, the shear stresses concentrated near the supports that have practically no significant effect on the flexural strength when the span length was long as in $25 \mathrm{~mm}$ length specimens.

When $10 \mathrm{~mm}$ length specimens polymerized from a distance of $0 \mathrm{~mm}$ light distance, which is clinically not realistic, and loaded at its centre, typically specimens failed at one of their edges. This may suggest that the edges of the specimens were not adequately polymerized compared to the center of the specimen. In fact, Weibull characteristics clearly denoted that 
specimen length in relation to light source distance combinations should be considered along with overlapping polymerization cycles when optimum photo-polymerization of the resin composites is anticipated. Accordingly, ISO 4049 (2000) [16] may be revised and specifications for photo-polymerization as a function of light attenuation parameters are to be scrutinized for photo-initiated dental polymers.

\section{Clinical Relevance}

This study indicated that specimen dimensions prepared in accordance with ISO 4049 do not allow for comparison of the effect of light attenuation distance during photopolymerization on the flexural strength of resin composite tested. Smaller specimen dimensions can reflect the clinical restoration scenarios and also could discriminate the variable effect of distance exceeding $0 \mathrm{~mm}$ on polymerization of resin composite.

\section{Acknowledgements}

The authors would like to thank VOCO GmbH, Cuxhaven, Germany for supplying the resin material used in this study.

\section{Conflict of Interest}

The authors report no conflicts of interest and no financial support for this study.

\section{References}

[1] Anusavice KJ. 1996. Physical properties of dental materials. Phillip's science of dental materials (10th edition). Philadelphia: W. B. Saunders. pp. 33-74. 
[2] Ferracane JL, Greener EH. The effect of resin formulation on the degree of conversion and mechanical properties of dental restorative resins. J. Biomed. Mater. Res. 1986;20:121131.

[3] Ferracane JL. Correlation between hardness and degree of conversion during the setting reaction of unfilled dental restorative resins. Dent. Mater. 1985;1:11-14.

[4] Ferracane JL, Mitchem JC, Condon JR, et al. Wear and marginal breakdown of composites with various degrees of cure. J. Dent. Res. 1997;76:1508-1516.

[5] Imazato S, Tarumi H, Kobayashi K, et al. Relationship between the degree of conversion and internal discoloration of light-activated composite. Dent. Mater. J. 1995;14:23-30.

[6] Lovell LG, Newman SM, Donaldson MM, et al. The effect of light intensity on double bond conversion and flexural strength of a model, unfilled dental resin. Dent. Mater. 2003;19:458-65.

[7] Bouschlicher MR, Rueggeberg FA, Wilson BM. Correlation of bottom-to-top surface microhardness and conversion ratios for a variety of resin composite composition. Oper. Dent. 2004;29:698-704.

[8] Calheiros FC, Kawano Y, Stansbury JW, et al. Influence of radiant exposure on contraction stress, degree of conversion and mechanical properties of resin composites. Dent. Mater. 2006;22:799-803.

[9] Rode KM, Kawano Y, Turbino ML. Evaluation of curing light distance on resin composite microhardness and polymerization. Oper. Dent. 2007;32:571-578.

[10] Silva EM da, Almeida GS, Poskus LT, et al. Relationship between the degree of conversion, solubility and salivary sorption of a hybrid and a nanofilled resin composite. J. App. Oral Sci. 2008;16:161-166. 
[11] Ruyter IE. Monomer system and polymerization. In: Vanherle G, Smith DC, eds. International Symposium on posterior composite resin dental restorative materials. St Paul, MN: Minnesota Mining \& Manufacturing Co. 1985;32:109-135.

[12] Hansen EK, Asmussen E. Visible-light-curing units: correlation between depth of cure and distance between exit window and resin surfasse. Acta Odontol. Scand. 1997;55:162166.

[13] Felix CA, Price RB. 2003. The effect of distance from light source on light intensity from curing lights. J. Adhes. Dent. 2003;5:283-291.

[14] Aravamudhan K, Rakowski D, Fan PL. Variation of depth of cure and intensity with distance using LED curing lights. Dent. Mater. 2006;22:988-994.

[15] International Standards Organization. 1992. ISO 4049: 1988 /Cor.1: 1992, Dentistry Resin-based Filling Materials, pp. 6-8. International Standards Organization, Geneva.

[16] International Standards Organisation. 2000. Dentistry-Polymer based filling, restorative and luting materials. ISO 4049. 3rd Edition, pp. 15-18.

[17] Kelly JR. Perspectives on strength. Dent. Mater. 1995;11:103-110.

[18] Shackelford JF. Glossary. In: Shackelford JF. Introduction to Materials Science for Engineers (4th edition). London: Prentice Hall International Limited, 1996; pp. 632-651.

[19] Lambrechts P, Braem M, Vanherle G. Buonocore memorial lecturer. Evaluation of clinical performance of posterior composite resins and dentin adhesives. Oper. Dent. 1987;12:53-78.

[20] Darvell BW. Uni-axial compression tests and the validity of indirect tensile strength. J. Mater. Sci. 1990;25:757-780.

[21] Palin WM, Fleming GJ, Burke JF, et al. The reliability in flexural strength testing of a novel dental composite. J. Dent. 2003;31:549-557. 
[22] Wheeler RC. Molars and central incisors. In: Wheeler RC. Textbook of Dental Anatomy and Physiology. Philadelphia: WB Saunders Company. 1965; pp. 125-283.

[23] Dionysopoulos P. The effect of secondary curing on flexural strength of composite resin. Odontostomatol. Proodos. 1994;48:19-23.

[24] Ferracane JL, Ferracane LL, Musanje L. Effect of light activation method on flexural properties of dental composites. Am. J. Dent. 2003;16:318-322.

[25] Yap AUJ, Teoh SH. Comparison of flexural properties of composite restoratives using the ISO and mini-flexural tests. J. Oral Rehabil. 2003;30:171-177.

[26] Palin WM, Fleming GJP, Marquis PM. The reliability of standardized flexural strength testing procedure for a light-activated resin-based composite. Dent. Mater. 2005;21:911919.

[27] Peutzfeldt A, Asmussen E. Resin composite properties and energy density of light-cure. J. Dent. Res. 2005;84:659-662.

[28] Smisson D, Diefenderfer K, Strother J. Effects of five thermal stressing regimens on the flexural and bond strengths of a hybrid resin composite. Oper. Dent. 2005;30:297-303.

[29] Douglas WH. Considerations for modelling. Dent. Mater. 1996;12:203-207.

[30] Kumar N. Inconsistency in the strength testing of dental resin-based composites among researchers. Pak. J. Med. Sci. 2013;29:205-210.

[31] Azillah M, Anstice H, Pearson G. Long-term flexural strength of three direct aesthetic restorative materials. J. Dent. 1998;26:177-182.

[32] Cabrera C, Pinzan A, Cabrera M, Henriques J, Janson G, Freitas M. Biometric study of human teeth. Dental Press J. Orthod. 2011;16:111-122.

[33] Caldas D, de Almeida J, Correr-Sobrinho L, et al. Influence of curing tip distance on resin composite Knoop hardness number, using three different light-curing units. Oper. Dent. 2003;28:315-320. 
[34] McNaught A, Wilkinson A. IUPAC compendium of chemical terminology. International Union of Pure and Applied Chemistry. 2nd ed Williston: Blackwell Science. 1997;19:458465.

[35] Watts D, Amer O, Combe E. Characteristics of visible-light activated composite systems. Br. Dent. J. 1984;156:209-215.

[36] Prati C, Chersoni S, Montebugnoli L, et al. Effect of the air, dentin and resin-based composite thickness on light intensity reduction. Am. J. Dent. 1999;12:231-234.

[37] El-Askary F, El-Korashy D. Influence of shade and light-curing distance on the degree of conversion and flexural strength of a dual-cure core build-up resin composite. Am. J. Dent. 2012;25:97-102. 


\section{Legends to figures and tables:}

\section{Figures:}

Figures. 1a-d. Schematic diagram representing the number and sequence of overlapping cycles of photo-polymerization for resin composite specimens with a length of a) $10 \mathrm{~mm}, \mathbf{b}$ ) $12 \mathrm{~mm}$, c) $15 \mathrm{~mm}$ and d) $25 \mathrm{~mm}$.

Figures. 2a-d. Schematic diagram representing distances from the tip of the photopolymerization device and the specimen surface a) $0 \mathrm{~mm}$, b) $2 \mathrm{~mm}$, c) $4 \mathrm{~mm}$, d) $8 \mathrm{~mm}$ distance. $\mathrm{RC}=$ Resin composite specimen in the silicon mould.

Figures. 3a-d. Schematic representation of span lengths corresponding to a) $10 \mathrm{~mm}$, b) 12 $\mathrm{mm}$, c) 15 and d) $25 \mathrm{~mm}$ length specimens during flexural strength test set-up.

\section{Tables:}

Table 1. Two-Way ANOVA for the effect of light attenuation distance, specimen dimensions and their interaction on the flexural strength of nano-hybrid resin composite.

Table 2. Mean flexural strength \pm standard deviations (MPa) of nano-hybrid resin composite as a function of specimen length and distance of the polymerization tip to the specimen surface.

Table 3. Weibull characteristics $(95 \% \mathrm{Cl})$ of shape $(m)$ and scale $(0)$ values using maximum likelihood estimation, in the order of $0,2,4,8 \mathrm{~mm}$ light attenuation distances for the specimens with $10,12,15$ and $25 \mathrm{~mm}$ length. 
A

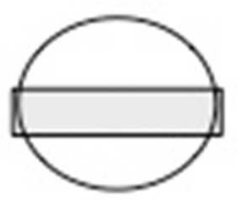

C

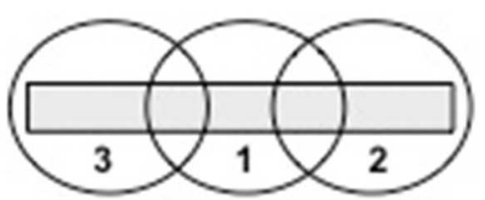

B

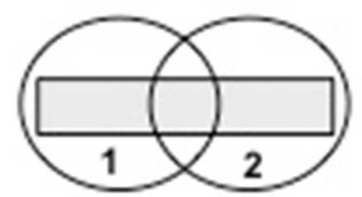

Figure 1

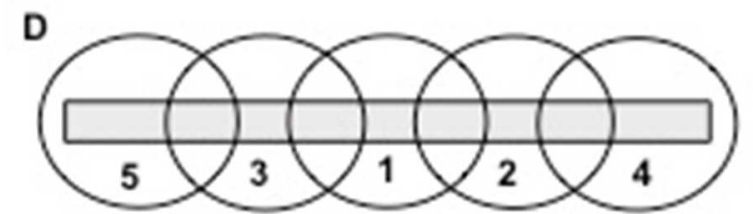

A

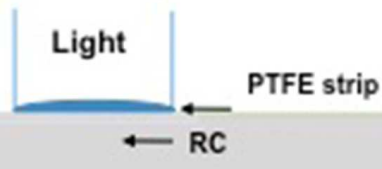

Silicon mould

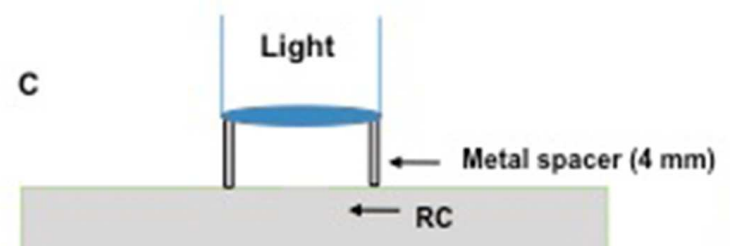

Silicon mould
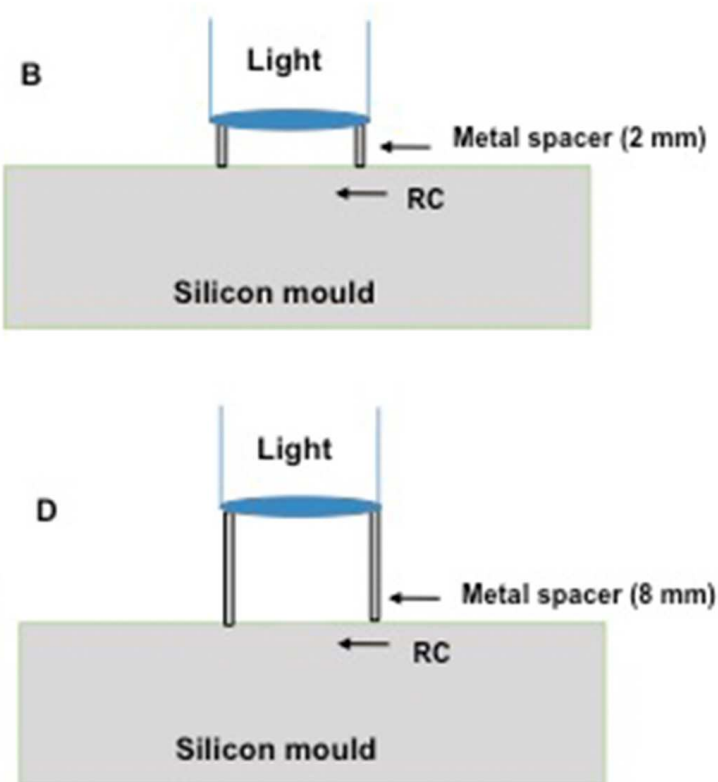

Figure 2 
A

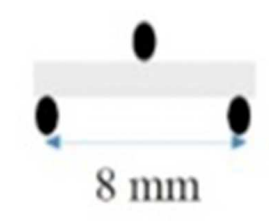

C

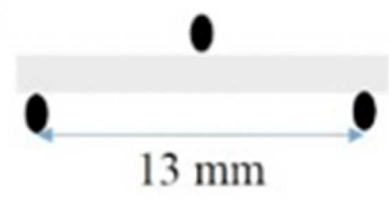

B

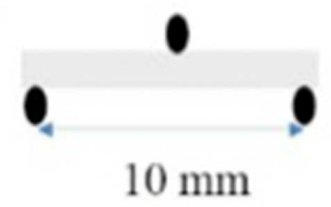

D
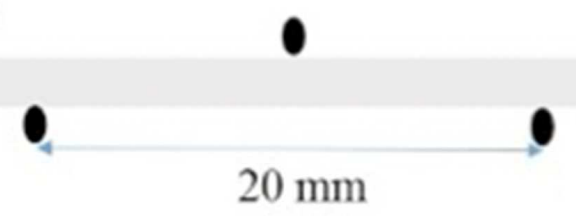

Figure 3 


\begin{tabular}{|c|c|c|c|c|c|}
\hline Source & $\begin{array}{c}\text { Type III Sum of } \\
\text { Squares }\end{array}$ & df & Mean Square & $\mathbf{F}$ & Sig. \\
\hline Corrected Model & $13152.271^{a}$ & 15 & 876.818 & 5.388 & $\leq 0.001$ \\
\hline Intercept & 2500460.021 & 1 & 2500460.021 & 15366.600 & $<0.001$ \\
\hline Light Distance & 4986.153 & 3 & 1662.051 & 10.214 & $\leq 0.001$ \\
\hline Dimension & 6137.058 & 3 & 2045.686 & 12.572 & $\leq 0.001$ \\
\hline Distance * Dimension & 2029.060 & 9 & 225.451 & 1.386 & 0.200 \\
\hline Error & 23431.745 & 144 & 162.720 & & \\
\hline Total & 2537044.037 & 160 & & & \\
\hline Corrected Total & 36584.016 & 159 & & & \\
\hline
\end{tabular}


Table 2: Mean flexure strength \pm standard deviations (MPa) of nano-hybrid resin composite as a function of specimen length and distance of polymerization tip to specimen surface.

\begin{tabular}{|c|c|c|c|c|c|}
\hline & $0 \mathrm{~mm}$ & $2 \mathrm{~mm}$ & $4 \mathrm{~mm}$ & $8 \mathrm{~mm}$ & $\begin{array}{c}\text { Total } \\
\text { (Dimension) }\end{array}$ \\
\hline $10 \mathrm{~mm}$ & $135.2 \pm 14.2^{\mathrm{aAB}}$ & $141.8 \pm 13.9^{\mathrm{aA}}$ & $127.2 \pm 12.4^{\mathrm{aAB}}$ & $125.4 \pm 8.1^{\mathrm{aB}}$ & $132.4 \pm 13.6^{\pi}$ \\
\hline $12 \mathrm{~mm}$ & $137.5 \pm 14.5^{\mathrm{aA}}$ & $127.3 \pm 15.9$ abAB & $118.3 \pm 9.3^{a b B}$ & $115.3 \pm 13^{a B}$ & $124.6 \pm 15.6^{\dagger}$ \\
\hline $15 \mathrm{~mm}$ & $130.0 \pm 13^{\mathrm{aA}}$ & $118.8 \pm 10.5^{\mathrm{bAB}}$ & $106.5 \pm 12.1^{\mathrm{bB}}$ & $111.8 \pm 13.3^{a B}$ & $116.8 \pm 14.8^{\ddagger}$ \\
\hline $25 \mathrm{~mm}$ & $127.9 \pm 14^{\mathrm{aA}}$ & $130.4 \pm 8.6^{\mathrm{abA}}$ & $122.8 \pm 12.7^{\mathrm{aA}}$ & $123.9 \pm 12.8^{\mathrm{aA}}$ & $126.3 \pm 12.8^{9 \dagger}$ \\
\hline $\begin{array}{c}\text { Total } \\
\text { (Distance) }\end{array}$ & $132.6 \pm 14^{\ddagger}$ & $129.6 \pm 14.7^{\ddagger}$ & $118.7 \pm 13.7^{\pi}$ & $119.1 \pm 13.5^{\pi}$ & \\
\hline \multicolumn{6}{|c|}{$\begin{array}{l}\text { Same superscript small letters within each column and capital letters within each raw are not statistically significant. } \\
\text { For the total dimension and total distance, means with the same superscript symbols within each column, and each } \\
\text { raw are not statistically significant }(\alpha=0.05) \text {. }\end{array}$} \\
\hline
\end{tabular}


Table 3: Weibull characteristics $(95 \% \mathrm{Cl})$ of shape $(m)$ and scale $(0)$ values using maximum likelihood estimation, in the order of $0,2,4,8 \mathrm{~mm}$ light attenuation distances for the specimens with 10, 12, 15 and $25 \mathrm{~mm}$ length.

\begin{tabular}{|c|c|c|c|c|c|c|c|c|}
\hline & \multicolumn{2}{|c|}{ 0 mm } & \multicolumn{2}{c|}{$\mathbf{2 ~ m m}$} & \multicolumn{2}{c|}{$\mathbf{4}$ mm } & \multicolumn{2}{c|}{} \\
\hline & $m$ & 0 & $m$ & 0 & $m$ & 0 & $m$ & 0 \\
\hline $\mathbf{1 0} \mathbf{~ m m}$ & 11.59 & 141.2 & 11.1 & 148 & 11.82 & 132.7 & 24.65 & 128.6 \\
\hline $\mathbf{1 2} \mathbf{~ m m}$ & 10.85 & 143.8 & 9.08 & 134.2 & 14.54 & 122.5 & 11.15 & 120.7 \\
\hline $\mathbf{1 5} \mathbf{~ m m}$ & 10.46 & 135.8 & 12.32 & 123.5 & 9.02 & 111.9 & 10.83 & 117.3 \\
\hline $\mathbf{2 5} \mathbf{~ m m}$ & 9.46 & 134.2 & 17.56 & 134.3 & 11.36 & 128.4 & 9.56 & 130.4 \\
\hline
\end{tabular}

